\title{
Assessment of multiple pharmacological mechanisms in the ascaris sensitive sheep model of allergic asthma
}

\author{
Michael Caniga', Janice D Woodhouse ${ }^{1}$, Alan Wilhelm¹, Malgorzata A Gil', Robbie McLeod ${ }^{1}$, Lily Y Moy ${ }^{1}$, \\ Michael A Crackower ${ }^{1}$, Thomas Miller ${ }^{1}$, William M Abraham², Milenko Cicmil ${ }^{1 *}$
}

From 2nd Cross Company Respiratory Symposium

Horsham, UK. 6-7 September 2012

\section{Background}

Asthma is a multifaceted disease that presents with a combination of reversible bronchoconstriction, inflammation, and airway remodeling. Historically, a variety of in vivo models have been used by preclinical investigators as surrogates for the disease. However, many of these models have significant limitations. For example, rodent models relying solely on TH2 mediated respiratory inflammation have inadequate predictability and clinical translatability because they can only recapitulate partial aspects of the human disease. In order to align with human Phase I allergen challenge experiments we used ascaris sensitive sheep model. This model enables us to investigate role of different mechanisms on early and late asthmatics responses.

\section{Methods and materials}

After inhaled ascaris antigen challenge, sheep display a classical airway response featuring an early airway response (EAR), a late airway response (LAR), and airway hyperreactivity (AHR), as described by Abraham et al. (1983) [1]. Compound can be administered either topically (via inhalation) or systemically prior to the inhaled challenge. A range of compounds and mechanisms have been investigated in this model.

\section{Results}

Standard of care anti-inflammatory compounds such as corticosteroids and leukotriene inhibitors show little inhibition of the EAR at low doses but completely inhibit the LAR and AHR. Novel anti-inflammatory targets such as Chemoattractant receptor-homologous molecule expressed on T-helper type 2 cells (CRTH2) inhibitor, MK7246, also show little inhibition of the EAR at low doses and blocked the LAR and AHR. Broncho-constrictors like the B2-adenergic antagonist, fomoterol, greatly inhibit the EAR ( 85\%) but have less of an effect on the LAR ( 60\%).

\section{Conclusion}

Cumulative data from this model has shown to be a good predictor for Phase 1 allergen challenge trial. Standard of care compounds and novel mechanisms used perform similarly in human trials as they did in ascaris sensitive sheep model. This model offers some key element of airways reactivity function similar to human asthma.

\footnotetext{
Authors' details

${ }^{1}$ Merck Research Laboratories, Boston, MA 02115, USA. ${ }^{2}$ Mount Sinai Medical Center, Miami Beach, FL 33140, USA.
}

Published: 14 August 2013

\section{Reference}

1. Abraham WM, Delehunt JC, Yerger L, Marchette B: Characterization of a late phase pulmonary response after antigen challenge in allergic sheep. Am Rev Respir Dis 1983, 128(5):839-44.

doi:10.1186/1476-9255-10-S1-P15

Cite this article as: Caniga et al:: Assessment of multiple

pharmacological mechanisms in the ascaris sensitive sheep model of allergic asthma. Journal of Inflammation 2013 10(Suppl 1):P15.

Merck Research Laboratories, Boston, MA 02115, USA

Full list of author information is available at the end of the article

(c) 2013 Caniga et al; licensee BioMed Central Ltd. This is an Open Access article distributed under the terms of the Creative Commons 